\section{Sung Min Kim, Byeong Sam Choi, Sungjoon Lee}

Department of Neurosurgery, Inje University Haeundae Paik Hospital, Busan, Korea

\section{Corresponding Author: \\ Sungjoon Lee \\ Department of Neurosurgery, Inje University Haeundae Paik Hospital, 875 Haeun-daero, Haeundae-gu, Busan 48108, Korea}

Tel: +82-51-797-0241

Fax: +82-51-797-0841

E-mail: potata98@naver.com

Received: December 18, 2017 Revised: December 21, 2017 Accepted: December 22, 2017
Copyright (C) 2017 by The Korean Spinal Neurosurgery Society

This is an open access article distributed under the terms of the Creative Commons Attribution Non-Commercial License (http://creativecommons.org/licenses/bync/4.0/) which permits unrestricted noncommercial use, distribution, and reproduction in any medium, provided the original work is properly cited.

\title{
Sudden Paraplegia Caused by Nontraumatic Cervical Disc Rupture: A Case Report
}

A 38-year-old man visited our Emergency Department for sudden onset paraplegia that occurred 1 hour ago. He felt a piercing pain in the posterior neck and became paraplegic while he was watching television, lying down on a sofa. Neurological examination showed motor power grades II-III in both arms and grade 0 in both legs. His cervical magnetic resonance imaging (MRI) showed a large ruptured disc at the C5-6 level, severely compressing the spinal cord. Emergency anterior cervical discectomy and fusion at C5-6 were performed. Because extensive cord swelling was observed on postoperative MRI, laminoplasty from C3 to C6 was performed 3 days after the initial operation. At a postoperative 8-month follow-up, the motor power was improved to grade III-IV- for both hands and grade IV- for both legs. Nontraumatic cervical disc rupture causing acute paraplegia is a very rare but possible event. Immediate neurologic assessment and thorough imaging studies to allow accurate diagnosis are crucial. Emergency surgical decompression is important and may lead to good neurological outcomes.

Key Words: Nontraumatic, Disc rupture, Disc herniation, Cervical disc, Paraplegia

\section{INTRODUCTION}

There are several disease entities of the spine that cause sudden onset paraplegia without any antecedent traumatic events. Usually, a cord lesion, specifically an acute bleeding one from intramedullary pathology such as vascular malformations or tumors, is considered to be the initial diagnosis. Acute cervical disc ruptures can cause severe cord compression and make a patient paraplegic. However, nontraumatic sudden onset paraplegia due to cervical disc herniation is very rare in that only approximately 10 cases have been reported in the literature $^{1-5,7,8)}$. We recently managed a patient who became suddenly paraplegic without any identifiable traumatic events, and we report this rare case herein.

\section{CASE REPORT}

A 38-year-old man visited our Emergency Department for sudden onset paraplegia that occurred 1 hour before his visit. He was lying on a sofa, watching television when he felt a piercing pain in the posterior neck and became quadriplegic within a few minutes. Neurologic examination showed motor grade II-III in both arms and grade 0 in both hands and legs. All the sensory scales below the neck were decreased. Pathologic reflexes were not observed.
Computed tomography and subsequent magnetic resonance imaging (MRI) of the cervical spine was performed. A large ruptured disc material was compressing the spinal cord severely at the C5-6 level (Fig. 1A-D). Emergency anterior cervical discectomy and fusion were performed. Follow-up cervical MRI was taken one day after the surgery. Severe cord swelling and high signal change on T2-weighted images of the C3-6 level were observed (Fig. 2). Because the patient's neurologic status did not improved at all, we performed laminoplasty from C3 to C6 3 days after the initial operation (Fig. 3).

Postoperative care was uneventful. Three weeks after the operation, the patient was transferred to the rehabilitation department. Approximately 6 weeks after the surgery, his right leg motor power was improved to grade II, but the left leg remained grade 0 . The motor power of the proximal upper extremities had fully recovered, but his hand grip motor power remained at grade II-III. At the postoperative 8-month follow-up, the motor power had improved to grade III-IV- for both hand grips and grade IV- for both legs. He could walk a short distance with assistance.

\section{DISCUSSION}

Acute paraplegia is an emergency condition that requires proper diagnosis and treatment in a very short time. With an obvious traumatic 
event, we should look for a spinal injury that is unstable enough to damage the spinal cord. If there is no notable antecedent injury, various etiologies should be considered ${ }^{3}$. However, it would be difficult to consider a cervical disc herniation to be the cause of nontraumatic acute paraplegia.

It has been reported that the thoracic spine is the most common site for nontraumatic acute myelopathy caused by disc herniation $^{7}$. Cervical disc herniation associated with acute paraplegia is rare in that only approximately 10 cases have been reported in the literature ${ }^{1-5,7,8)}$. C6-7 was the most common site, followed by $\mathrm{C} 4-5$ and $\mathrm{C} 3-4$, respectively. Interestingly, no report of C5-6 disc herniation associated with nontraumatic acute paraplegia is present so far. Ours is the first reported $\mathrm{C}^{-6} 6$ case. This is quite unusual because C5-6 is not the most common site for cervical disc herniation that causes myelopathy or radiculopathy. However, the possibility of under reporting should be considered.
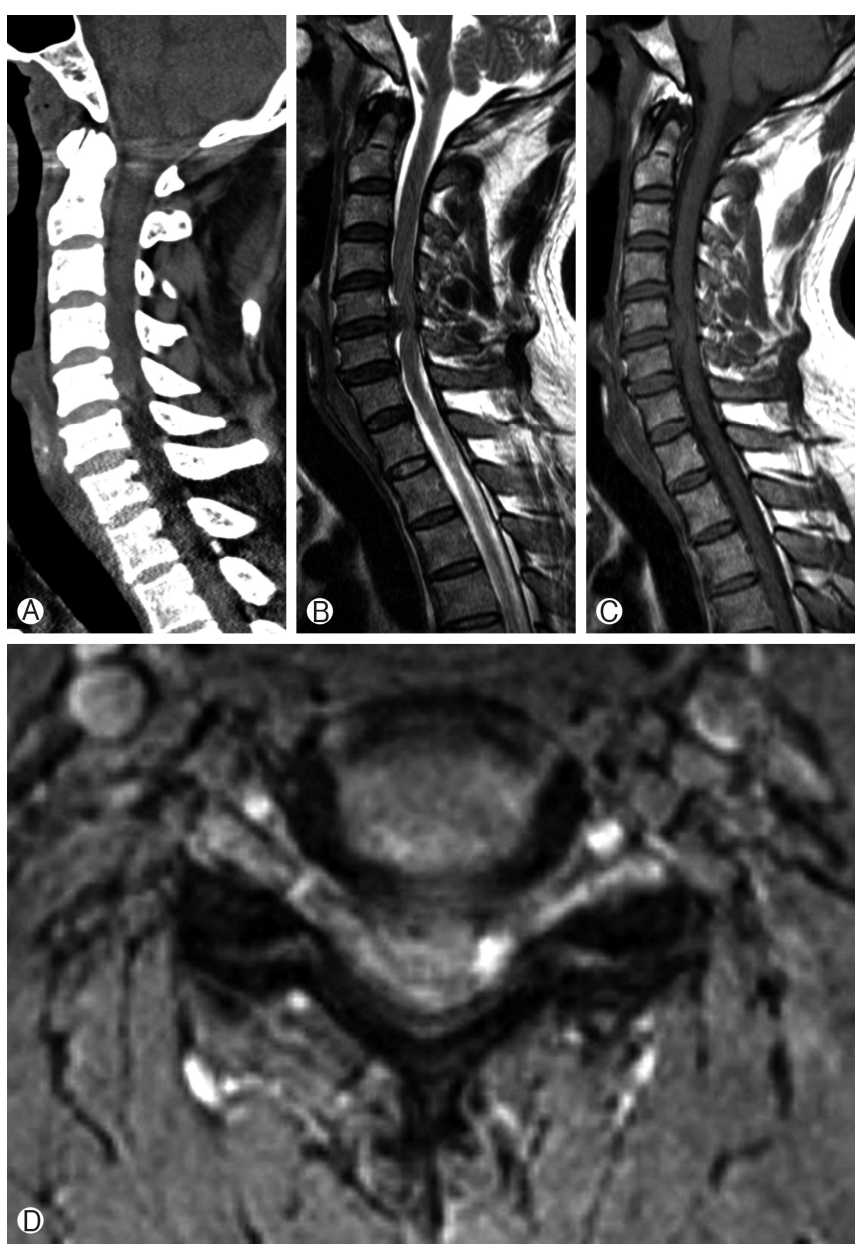

Fig. 1. (A) Cervical spine computed tomography, midsagittal reconstructed image. A highly attenuated mass lesion occupying the anterior 1/2 of the spinal canal at the C5-6 level was observed. (B-D) Sagittal T2-, T1-, and axial T2-weighted magnetic resonance imaging, respectively. A ruptured disc from the $\mathrm{C} 5-6$ disc was severely compressing the spinal cord.

Several reports have demonstrated the presence of neck pain and myelopathic symptoms such as progressive motor weakness and/or numbness in arms and legs, a few to several months before the acute onset of paraplegia ${ }^{3,78)}$. Our patient denied any past medical history and symptoms related to cervical disc herniation at the time of the visit, but later he told us that he had

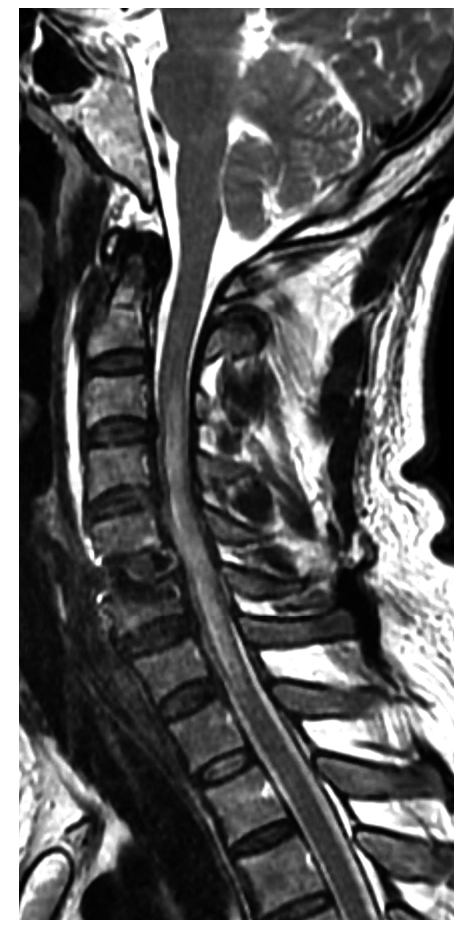

Fig. 2. Sagittal T2-weighted imaging taken 3 days after the initial operation revealed a severely swollen spinal cord with extensive high signal changes from $\mathrm{C} 3$ to C7.

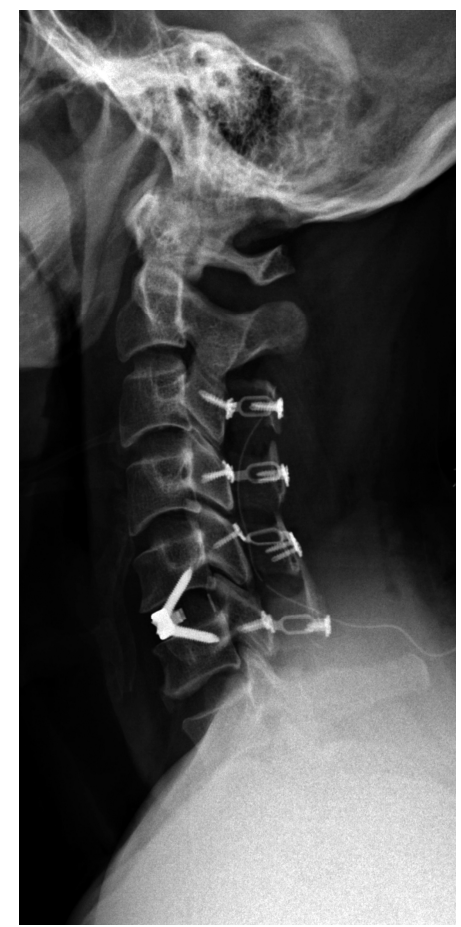

Fig. 3. Immediate postoperative lateral radiography taken after the second operation. 
experienced neck pain 2 months before the onset of paraplegia. In addition, multilevel cervical disc herniations and a relatively narrow cervical spinal canal are commonly reported ${ }^{2,3,7,8)}$. It is well known that flexed posture of the spine increases the intradiscal pressure ${ }^{6}$, providing the possibility that disc material could be extruded during spinal motions within the physiologic range. However, the volume of a cervical disc is small, and most extruded disc materials are not big enough to make a patient paraplegic. If the spinal canal is narrow and the spinal cord is already compressed by a preexisting disc herniation, the probability of the emergence of acute paraplegia would increase. Though it is a very small risk, however, one should keep in mind that sudden onset severe neurologic deterioration could occur in patients with narrow spinal canal.

Cervical disc herniations present gradual or stepwise symptom progression in usual clinical settings. According to the acute progression of severe neurological injuries, many authors have been convinced of the presence of a cascade of secondary injury mechanisms. Vascular insufficiency, by disc material compressing the anterior spinal artery, is the most commonly suggested mechanism leading to secondary spinal cord injury. However, such opinions have been suggested without any back-up evidence. Thus, the exact mechanisms leading to acute neurological deterioration should be elucidated in future studies.

Most authors have treated their patients with an anterior approach, removing ruptured disc material and fusing the affected segment $^{3,5,8)}$. In one report, the authors performed laminoplasty after anterior cervical discectomy and fusion, similar to our case ${ }^{\gamma}$. Treatment outcomes are variable. Some reports show rapid neurological recovery and good functional outcomes ${ }^{3-5,8)}$. However, other reports present sustained nonambulatory states after 1 year of follow-up despite early surgical treatment ${ }^{2,7}$. It seems that the clinical course is similar to that of traumatic acute spinal cord injuries, and the outcome depends on the amount of cord injury at the time of insult after the disc rupture. In the present case, the patient showed grade III to IV- motor improvements of both lower extremities 8 months after the surgery. The neurologic recovery appeared slow in progress, and the neurologic outcome was somewhat unsatisfactory. However, it is certain that precise assessments and early surgical treatments are man- datory for good prognoses in acute paraplegic patients with a nontraumatic cervical disc rupture.

\section{CONCLUSION}

Nontraumatic cervical disc rupture causing sudden onset quadriplegia is a very rare but possible event. To make an accurate diagnosis, immediate neurologic assessments and thorough imaging work-ups are mandatory. Subsequent urgent surgical decompression is important and may lead to good neurologic outcomes.

\section{CONFLICT OF INTEREST}

No potential conflict of interest relevant to this article was reported.

\section{REFERENCES}

1. Chen SH, Hui YL, Yu CM, Niu CC, Lui PW: Paraplegia by acute cervical disc protrusion after lumbar spine surgery. Chang Gung Med J 28:254-257, 2005.

2. Goh HK, Li YH: Non-traumatic acute paraplegia caused by cervical disc herniation in a patient with sleep apnoea. Singapore Med J 45:235-238, 2004

3. Liu C, Huang Y, Cai HX, Fan SW: Nontraumatic acute paraplegia associated with cervical disk herniation. J Spinal Cord Med 33: 420-424, 2010

4. Lourie H, Shende MC, Stewart DH Jr: The syndrome of central cervical soft disk herniation. JAMA 226:302-305, 1973

5. Mahore A, Agarwal M, Ramdasi R, Tikeykar V: Migrated disc at cervicothoracic junction presenting as acute paraplegia. Asian Spine J 9:449-451, 2015

6. Pospiech J, Stolke D, Wilke HJ, Claes LE: Intradiscal pressure recordings in the cervical spine. Neurosurgery 44:379-384, 1999

7. Suzuki T, Abe E, Murai H, Kobayashi T: Nontraumatic acute complete paraplegia resulting from cervical disc herniation: a case report. Spine (Phila Pa 1976) 28:E125-128, 2003

8. Ueyama T, Tamaki N, Kondoh T, Miyamoto H, Akiyama H, Nagashima T: Non-traumatic acute paraplegia associated with cervical disc herniation: a case report. Surg Neurol 52:204-206, 1999 